\title{
A Community-Based Physical Activity Counselling Program for People With Knee Osteoarthritis: Feasibility and Preliminary Efficacy of the Track-OA Study
}

Linda C Li ${ }^{1,2}, \mathrm{PT}, \mathrm{PhD}$; Eric C Sayre ${ }^{2}, \mathrm{PhD}$; Hui Xie ${ }^{3}, \mathrm{PhD}$; Cam Clayton ${ }^{2}, \mathrm{MSc}$; Lynne M Feehan ${ }^{1,4}, \mathrm{PT}, \mathrm{PhD}$

\footnotetext{
${ }^{1}$ Department of Physical Therapy, University of British Columbia, Vancouver, BC, Canada

${ }^{2}$ Arthritis Research Canada, Richmond, BC, Canada

${ }^{3}$ Faculty of Health Sciences, Simon Fraser University, Burnaby, BC, Canada

${ }^{4}$ Rehabilitation Program, Fraser Health, Surrey, BC, Canada
}

Corresponding Author:

Linda C Li, PT, PhD

Arthritis Research Canada

5591 No. 3 Road

Richmond, BC, V6X 2 C7

Canada

Phone: 16042074020

Email: 1 li@arthritisresearch.ca

\section{Abstract}

Background: Physical activity can improve health outcomes in people with knee osteoarthritis (OA); however, participation in physical activity is very low in this population.

Objective: The objective of our study was to assess the feasibility and preliminary efficacy of the use of wearables (Fitbit Flex) and telephone counselling by a physical therapist (PT) for improving physical activity in people with a physician-confirmed diagnosis of knee OA, or who have passed 2 validated criteria for early OA.

Methods: We conducted a community-based feasibility randomized controlled trial. The immediate group ( $\mathrm{n}=17)$ received a brief education session by a physical therapist, a Fitbit Flex activity tracker, and a weekly telephone call for activity counselling with the physical therapist. The delayed group $(n=17)$ received the same intervention 1 month later. All participants were assessed at baseline (T0), and the end of 1 month (T1) and 2 months (T2). Outcomes were (1) mean moderate to vigorous physical activity time, (2) mean time spent on sedentary behavior, (3) Knee Injury and Osteoarthritis Outcome Score (KOOS), and (4) Partners in Health Scale. Feasibility data were summarized with descriptive statistics. We used analysis of covariance to evaluate the effect of the group type on the outcome measures at T1 and T2, after adjusting for blocking and T0. We assessed planned contrasts of changes in outcome measures over measurement periods.

Results: We identified 46 eligible individuals; of those, 34 (74\%) enrolled and no one dropped out. All but 1 participant adhered to the intervention protocol. We found a significant effect, with the immediate intervention group having improved in the moderate to vigorous physical activity time and in the Partners in Health Scale at T0 to T1 compared with the delayed intervention group. The planned contrast of the immediate intervention group at T0 to T1 versus the delayed group at T1 to T2 showed a significant effect in the sedentary time and the KOOS symptoms subscale, favoring the delayed group.

Conclusions: This study demonstrated the feasibility of a behavioral intervention, supported by the use of a wearable device, to promote physical activity among people with knee OA.

Trial Registration: ClinicalTrials.gov NCT02313506; https://clinicaltrials.gov/ct2/show/NCT02313506 (Archived by WebCite at http://www.webcitation.org/6r4P3Bub0)

(JMIR Mhealth Uhealth 2017;5(6):e86) doi: 10.2196/mhealth.7863

\section{KEYWORDS}

osteoarthritis; physical activity; sedentary behavior; sedentary lifestyle; wearables; digital technology; fitness trackers; exercise 


\section{Introduction}

It is well known that physical activity can improve pain, mobility, and quality of life in people with knee osteoarthritis (OA) [1-4]. Being physically active is important in OA management partly due to its effect in managing weight [5-7]; however, participation in physical activity is very low in this population. A 2011 study using accelerometers found that over $90 \%$ of people with knee OA did not meet the physical activity guidelines of 150 minutes of moderate to vigorous physical activity (MVPA) per week [8]. A survey of 1713 people with knee or hip OA in Canada reported that fewer than half walked "one or more hours per week for exercise," even among people with mild symptoms [9]. The 2011 Canadian Community Health Survey also found that $57 \%$ of people with arthritis were physically inactive during their leisure time, compared with $46 \%$ of those without arthritis (Multimedia Appendix 1). These findings concur with a 2013 systematic review that found that only $13 \%$ of people with OA met physical activity guidelines [10].

The current public health message is that being active is good, but people with OA may have difficulties with MVPA due to pain [11-13]. In this situation, people can still benefit from maintaining a level of light activity. Studies have indicated that a sedentary lifestyle (ie, too much sitting) is a predictor of poor health outcomes [14-18]. The detrimental health effect of sitting too much is independent of the person's activity level. Interestingly, light activities, even done below the moderate-intensity level (eg, daily tasks done while standing or walking slowly), can provide health benefits [19-21]. Hence, there is a need for interventions to both improve the time spent in MVPA and decrease sitting time.

Nowadays, wearable devices are popular in the consumer space to support an active lifestyle. Evidence suggests they may also be beneficial in clinical populations. For example, Talbot et al [22] combined a pedometer-driven walking program with self-management education for people with knee OA and found an average increase of $23 \%$ in individuals' daily steps and of $21 \%$ in isometric quadriceps muscle strength, compared with an education only group [22]. A 2007 meta-analysis of 8 randomized controlled trials (RCTs) reported a significant difference in the improvement of physical activity among pedometer users compared with controls (mean difference 2491 steps/day, 95\% CI 1098-3885) [23].

Compared with pedometers, wearable devices such as fitness bands and smart watches offer additional features, such as the ability to track the intensity of activities and to visualize activity performance over time. These features enable individuals to set specific goals, monitor progress, and obtain real-time feedback on goal attainment. Despite their popularity, the value of wearables to improve physical activity behavior has been challenged. In a review of 13 consumer wearables, Lyons et al [24] concludes that these devices usually include motivational techniques, such as self-monitoring and real-time feedback, but rarely address skills such as action planning and problem solving, which are essential to changing physical activity behavior. In a systematic review of 11 studies evaluating wearables (1272 participants), Lewis et al [25] found preliminary evidence of improvement in physical activity participation and body weight, but no difference when compared with other behavioral change interventions. Only 1 of the included studies was deemed to be of high quality. These results suggest that future research should develop better strategies to incorporate wearables in multifaceted physical activity interventions, rather than evaluating wearables as a standalone tool. Moreover, more rigorous research design should be employed in future RCTs. The purpose of our study was, therefore, to assess the feasibility of a strategy, which combines the use of wearables and telephone counselling by a physical therapist (PT), for improving physical activity behavior in people with knee OA. The results will inform the development of a community-based RCT.

\section{Methods}

\section{Study Design and Participant Eligibility}

The Track-OA feasibility study [26] used a randomized, delayed-control design, whereby the randomization determined the timing of when the intervention was provided (ie, immediately vs a 1-month delay). As such, preliminary efficacy could be assessed within a conventional RCT (ie, with an intervention group and a control group) at 1 month, while all participants received the intervention after 1 month. This study design is the best suited for complex interventions with components that are likely beneficial and present a low risk to participants (eg, promoting physical activity). By ensuring that all participants receive the intervention at the end of a study, this design might promote protocol compliance.

Eligible individuals were patients who had a physician-confirmed diagnosis of knee OA, or passed 2 criteria for early OA: (1) being age 50 years or older, and (2) having experienced pain or discomfort in or around the knee during the previous year lasting 28 or more separate or consecutive days. In a community-based study by Marra et al [27], 191 of 195 (98.0\%) urban-dwelling participants who met these criteria also met the American College of Rheumatology clinical criteria for knee OA [28].

We excluded individuals who (1) had a diagnosis of inflammatory arthritis, connective tissue diseases, fibromyalgia, or gout, (2) had used disease-modifying antirheumatic drugs or gout medications, (3) had knee arthroplasty, (4) were on the waitlist to receive total knee arthroplasty, (5) had acute knee injury in the past 6 months, (6) did not have an email address or daily access to a personal computer with Internet access, (7) had a body mass index of $40 \mathrm{~kg} / \mathrm{m}^{2}$ or more, (8) had received a steroid injection in the last 6 months, (9) had received hyaluronate injection in a knee in the last 6 months, (10) were using medications that impaired activity tolerance (such as $\beta$-blockers), or (11) had an inappropriate level of risk for increasing their unsupervised physical activity. Potential participants completed the Physical Activity Readiness Questionnaire (PAR-Q; 2014 version) [29]. If the PAR-Q identified a potential risk, we required physician confirmation to ensure that the person was able to be physically active without the supervision of a health care professional. 
We recruited participants from 3 sources: (1) postings on Facebook, Twitter, Kijiji, Craigslist, and the Arthritis Research Canada website, (2) emails sent by the Arthritis Consumer Experts (Vancouver, BC, Canada), a nonprofit patient education organization, to their patient members, and (3) emails sent by the Vancouver Coastal Health Research Institute (Vancouver, $\mathrm{BC}$, Canada) to its staff. Interested individuals were invited to contact the research coordinator, who provided details about the study, screened respondents for eligibility, and obtained their informed consent.

After completing the baseline assessment, participants were randomly assigned to the immediate group or the delayed group in a 1:1 allocation ratio. The delayed group received the same intervention as the immediate group after a 1-month wait. Random numbers were generated in variable block sizes for the random allocation.

\section{Intervention}

The intervention involved participants attending a 1.5-hour session, where they received (1) a standardized group education session about physical activity, (2) a Fitbit Flex (Fitbit, Inc, San Francisco, CA, USA), and (3) individual weekly activity counselling with a PT by telephone. The education session, delivered in groups of 2 to 3 participants, addressed the benefits of physical activity, the detrimental effects of sedentary behavior, and ways to be active without aggravating OA symptoms. The counselling component followed the brief action planning approach [30], whereby the PT guided participants to identify their activity goals, develop an action plan, identify barriers and solutions, and then rate their confidence in executing the plan. The process was repeated until the confidence rating reached at least 7 out of 10 , indicating that the person was confident about implementing the plan. For sedentary behavior, the PT began by asking participants to estimate their sitting time in a normal day and identify ways to break up the sitting time. They then repeated the goal setting and confidence assessment.

Participants were then provided a Fitbit to be worn at the wrist of the nondominant side to track their physical activity behavior. They were instructed to wear the fitness band 24 hours a day except during water-based activity or when charging the device. The data were wirelessly synchronized with Fitbit's online dashboard that could be viewed only by the participants and their study PTs. During the intervention period, the PT reviewed each individual's physical activity on the dashboard and progressively modified the activity goals during 4 weekly 20-minute telephone calls. Participants could also contact the PT via email. At the end of the intervention, they could keep the Fitbit, but no longer had access to the PT.

\section{Feasibility Assessment}

Guided by Bowen et al [31] and Thabane et al [32], the feasibility assessment focused on implementation, practicality, and preliminary efficacy. We measured implementation by the recruitment rate, dropout rate, adherence to the study protocol, and equipment retention. We aimed to achieve the following: (1) at least $80 \%$ of eligible individuals agreeing to participate, (2) no more than $10 \%$ dropping out, (3) at least $85 \%$ adhering to the intervention and assessment protocol, and (4) no more than $10 \%$ loss or malfunction of the 20 SenseWear accelerometer devices (BodyMedia, Pittsburgh, PA, USA) used in the study (for measuring the primary outcome; see below). We assessed practicality by self-reported adverse events and adherence to the assessment protocol. Specifically, participants were required to wear a SenseWear armband monitor for at least 20 hours during at least 4 of the 7 days of each evaluation period [33] and to complete all questionnaires within 7 days of the scheduled date. We assessed preliminary efficacy by examining outcome measures at baseline, and at the end of months 1 and 2.

\section{Outcome Measures}

The primary outcome was mean time spent in bouted MVPA per day. We defined a bout as at least 10 consecutive minutes at the level of at least 3 metabolic equivalent tasks (METs; ie, the lower bound of MVPA), with allowance for interruption of up to 2 minutes below the threshold [34]. Participants received a SenseWear Mini armband sensor by courier and wore it 24 hours a day for 7 consecutive days, with the exception of removal for water-based activities. Unlike Fitbit, which is a commercial activity tracker with important limitations in measurement accuracy [35], SenseWear is a research-based accelerometer and sensor with established measurement properties [36]. Tierney et al [37] showed that SenseWear is a valid tool for estimating energy expenditure during daily activities in people with arthritis (intraclass correlation coefficient 0.72). Additional analysis was performed with a cutoff at 4 or more METs, which reflects an activity level of brisk or faster walking (ie, purposeful activities) [38].

Secondary outcomes were the mean time spent in sedentary behavior, the Knee Injury and Osteoarthritis Outcome Score (KOOS) [39,40], and the Partners in Health Scale [41]. Compared with Fitbit, SenseWear is a superior outcome measure because of its ability to differentiate between sedentary and light activities [36]. We calculated the mean daily time spent with an energy expenditure of at least 1.5 METs, occurring in bouts of more than 20 minutes during waking hours $[18,21,42,43]$. The KOOS consists of 5 subscales: Pain, Symptoms, Activity of Daily Living, Sports and Recreation Function, and Knee-related Quality of Life. It was originally developed for people recovering from anterior cruciate ligament and meniscus injury and has been validated in people with OA $[39,40]$. The Partners in Health Scale is a 12-item measure designed to assess perceived self-management capacity via subjective knowledge of the health condition and treatment, and perceived self-management behavior (eg, adopting a healthy lifestyle) (Cronbach alpha=.82) [41]. We also tracked self-reported adverse events (falls, cardiovascular and musculoskeletal events) [44] using a monthly log completed by the participants. 
Table 1. Baseline characteristics of immediate intervention and delayed intervention participants.

\begin{tabular}{|c|c|c|c|c|}
\hline Characteristics & $\begin{array}{l}\text { All } \\
(\mathrm{N}=34)\end{array}$ & $\begin{array}{l}\text { Immediate intervention } \\
(\mathrm{n}=17)\end{array}$ & $\begin{array}{l}\text { Delayed intervention } \\
(\mathrm{n}=17)\end{array}$ & $P$ value $^{\mathrm{a}}$ \\
\hline Women, $\mathrm{n}(\%)$ & $28(82)$ & $14(82)$ & $14(82)$ & $\mathrm{N} / \mathrm{A}^{\mathrm{b}}$ \\
\hline Age in years, mean (SD) & $55.5(8.6)$ & $52.3(9.7)$ & $58.7(6.0)$ & .03 \\
\hline Marital status, n (\%) & & & & .40 \\
\hline Married or common law & $25(74)$ & $11(65)$ & $14(82)$ & \\
\hline Separated or divorced & $5(15)$ & $4(24)$ & $1(6)$ & \\
\hline Widowed, never married, or other & $4(12)$ & $2(12)$ & $2(12)$ & \\
\hline Gross annual household income in Can \$, n (\%) & & & & .52 \\
\hline$\leq 12,000$ & $2(6)$ & $1(6)$ & $1(6)$ & \\
\hline $12,001-24,000$ & $1(3)$ & 0 & $1(6)$ & \\
\hline $24,001-40,000$ & $2(6)$ & 0 & $2(12)$ & \\
\hline $40,001-60,000$ & $5(15)$ & $4(24)$ & $1(6)$ & \\
\hline $60,001-80,000$ & 0 & 0 & 0 & \\
\hline $80,001-100,000$ & $3(9)$ & $2(12)$ & $1(6)$ & \\
\hline$>100,000$ & $14(41)$ & $7(41)$ & $7(41)$ & \\
\hline No answer & $7(21)$ & $3(18)$ & $4(24)$ & \\
\hline $\mathrm{OA}^{\mathrm{c}}$ diagnosis, $\mathrm{n}(\%)$ & & & & .73 \\
\hline Yes & $20(59)$ & $11(65)$ & $9(53)$ & \\
\hline No, but met the "likely OA" criteria & $14(41)$ & $6(35)$ & $8(47)$ & \\
\hline "In general, would you say your health is...", n (\%) & & & & .15 \\
\hline Excellent & $6(18)$ & $5(29)$ & $1(6)$ & \\
\hline Very good & $11(32)$ & $5(29)$ & $6(35)$ & \\
\hline Good & $13(38)$ & $4(26)$ & $9(53)$ & \\
\hline Fair & $4(12)$ & $3(18)$ & $1(6)$ & \\
\hline Poor & 0 & 0 & 0 & \\
\hline \multicolumn{4}{|c|}{ “Compared with 1 year ago, how would you rate your health in general now?”, n (\%) } & .25 \\
\hline Much better & $1(3)$ & $1(6)$ & 0 & \\
\hline Somewhat better & $1(3)$ & 0 & $1(6)$ & \\
\hline About the same & $27(79)$ & $15(88)$ & $12(71)$ & \\
\hline Somewhat worse & $5(15)$ & $1(6)$ & $4(24)$ & \\
\hline Much worse & 0 & 0 & 0 & \\
\hline Number of comorbid conditions, median ( 25 th; 75 th percentile) & $2.5(2.0 ; 4.0)$ & $3.0(2.0 ; 4.0)$ & $2.0(2.0 ; 3.0)$ & 0.53 \\
\hline Body mass index in $\mathrm{kg} / \mathrm{m}^{2}$, mean (SD) & $27.2(4.7)$ & $29.1(4.5)$ & $25.4(4.2)$ & 0.02 \\
\hline
\end{tabular}

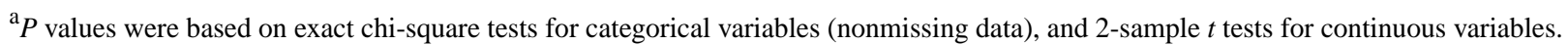

${ }^{\mathrm{b}} \mathrm{N} / \mathrm{A}$ : not applicable.

${ }^{\mathrm{c}} \mathrm{OA}$ : osteoarthritis. 
Table 2. Feasibility assessment.

\begin{tabular}{|c|c|c|c|c|}
\hline Feasibility component & Criteria & $\begin{array}{l}\text { All participants } \\
(\mathrm{N}=34)\end{array}$ & $\begin{array}{l}\text { Immediate group } \\
(\mathrm{n}=17)\end{array}$ & $\begin{array}{l}\text { Delayed group } \\
(\mathrm{n}=17)\end{array}$ \\
\hline Recruitment rate & $\begin{array}{l}\geq 80 \% \text { of eligible individuals agreeing to } \\
\text { participate }\end{array}$ & $\begin{array}{l}74 \%(34 / 46 \text { eligi- } \\
\text { ble) }\end{array}$ & $\mathrm{N} / \mathrm{A}^{\mathrm{a}}$ & N/A \\
\hline Dropout rate & $\leq 10 \%$ of participants dropping out & $0 \%$ & $0 \%$ & $0 \%$ \\
\hline $\begin{array}{l}\text { Adherence to intervention and assessment } \\
\text { protocol }\end{array}$ & $\begin{array}{l}\geq 85 \% \text { participants adhering to the study } \\
\text { protocol }\end{array}$ & $\begin{array}{l}88 \%(30 / 34 \text { en- } \\
\text { rolled) }\end{array}$ & $\begin{array}{l}88 \%(15 / 17 \text { en- } \\
\text { rolled) }\end{array}$ & $\begin{array}{l}88 \%(15 / 17 \text { en- } \\
\text { rolled })\end{array}$ \\
\hline Loss or malfunction of SenseWear & $\leq 10 \%$ SenseWear loss or malfunction & $0 \%$ & $0 \%$ & $0 \%$ \\
\hline
\end{tabular}

${ }^{\mathrm{a}} \mathrm{N} / \mathrm{A}$ : not applicable.

\section{Sample Size and Data Analysis}

With the resources available for the feasibility study, we aimed to recruit 30 participants within an 8-week period. We used descriptive statistics to summarize the feasibility variables and baseline variables of the 2 groups. We explored preliminary efficacy using intention-to-treat analysis. Q-Q plots were used to assess normality of the outcome variables. We conducted analysis of covariance to evaluate the effect of the group type (immediate vs delayed) on the outcome measures assessed at the end of 1 month (T1) and 2 months (T2), after adjusting for blocking and baseline (T0). We assessed 3 planned contrasts of changes in outcome measures over the measurement periods. The first contrast compared T0 to T1 between the 2 groups to determine whether the intervention was superior to the control. The second contrast compared $\mathrm{T} 0$ to $\mathrm{T} 1$ in the immediate group against $\mathrm{T} 1$ to $\mathrm{T} 2$ in the delayed group. The third contrast compared $\mathrm{T} 0$ to $\mathrm{T} 1$ in the immediate group against $\mathrm{T} 0$ to $\mathrm{T} 2$ in the delayed group. The last 2 models assessed whether the 1-month delay had an impact on the effect of the intervention.

We assessed the impact of missing data on the estimated effects of group assignment using imputation methods as described in van Buuren [45]. Specifically, we generated 10 imputed values using alternative random variates derived in a linear regression model, which included group, sex, baseline age, and baseline body mass index as predictors. We repeated the analyses using the 10 imputed values, and compared the conclusions and estimates against the main analysis, which assumed that data were missing at random.

\section{Ethics Approval}

The research protocol was approved by the University of British Columbia Clinical Research Ethics Board (application number: H14-02631), was registered with ClinicalTials.gov (NCT02313506), and has been published in the peer-reviewed literature [26].

\section{Results}

Between January and March, 2015 (7 weeks), 149 people expressed an interest to participate, and 46 met the eligibility criteria. Of those, 34 were enrolled and completed the study (Figure 1). The majority of participants were women $(n=28$,
$82 \%$ ), with the immediate group (mean age 52.3, SD 9.7 years; $\mathrm{n}=17$ ) younger than the delayed group (mean 58.7, SD 6.0 years; $\mathrm{n}=17)$. A total of 20 participants $(59 \%)$ reported a diagnosis of $\mathrm{OA}$, and $14(41 \%)$ met the "likely OA" criteria without a diagnosis. Among the participants, 17 rated their health as "very good" or "excellent." The mean body mass index was 27.2 (SD 4.7) $\mathrm{kg} / \mathrm{m}^{2}$, with the immediate group (mean 29.1, SD 4.5) higher than the delayed group (mean 25.4, SD 4.2) (Table 1).

\section{Feasibility}

Our recruitment strategy identified 46 eligible individuals; of those, 34 (74\%) enrolled and none dropped out (Table 2). All but 1 participant adhered to the intervention protocol. All participants completed the assessments as per protocol at T0 and T1. Participants were required to wear a SenseWear (the primary outcome measure) for at least 4 days [46], with each day requiring less than 4 hours of off-body time to be included in the analyses. All 34 participants met these wear criteria at T0 (mean number of days worn: 5.9, SD 0.3; mean off-body time: 23.1, SD 13.6 minutes) and T1 (mean number of days worn: 5.6, SD 0.7; mean off-body time: 24.8, SD 18.0 minutes). At T2, 31 participants adhered to the wear criteria (mean number of days worn: 5.7, SD 0.6; mean off-body time: 38.4, SD 27.9 minutes). In the delayed group, 1 participant did not complete the outcome measures.

\section{Preliminary Efficacy}

Figure 2 shows the results of outcome measures from 3 time points. Prespecified contrast analyses revealed a significant effect whereby the immediate group improved in the MVPA ( $\geq 3$ METs) time at T0 to T1 compared with the delayed group (contrast coefficient $-31.1,95 \% \mathrm{CI}-56.6$ to $-5.7 ; P=.02$ ) (Table 3 ). We also found a significant effect in the Partners in Health Scale scores at T0 to T1 (contrast coefficient 10.9, 95\% CI 2.5-19.3; $P=.02$ ). The planned contrast of the immediate group at $\mathrm{T} 0$ to $\mathrm{T} 1$ versus the delayed group at $\mathrm{T} 1$ to $\mathrm{T} 2$ showed a significant effect in sedentary time (contrast coefficient -83.6 , $95 \% \mathrm{CI}-154.1$ to $-13.1 ; P=.03$ ) and the KOOS symptoms subscale (contrast coefficient $6.9,95 \%$ CI $0.4-13.5 ; P=.048$ ), favoring the delayed group at $\mathrm{T} 1$ to $\mathrm{T} 2$. We found no significant effect in any outcome measures in the contrasts comparing the immediate group at T0 to T1 with delayed group at T0 to T2. 
Figure 1. Consolidated Standards of Reporting Trials (CONSORT) flowchart. IQR: interquartile range.

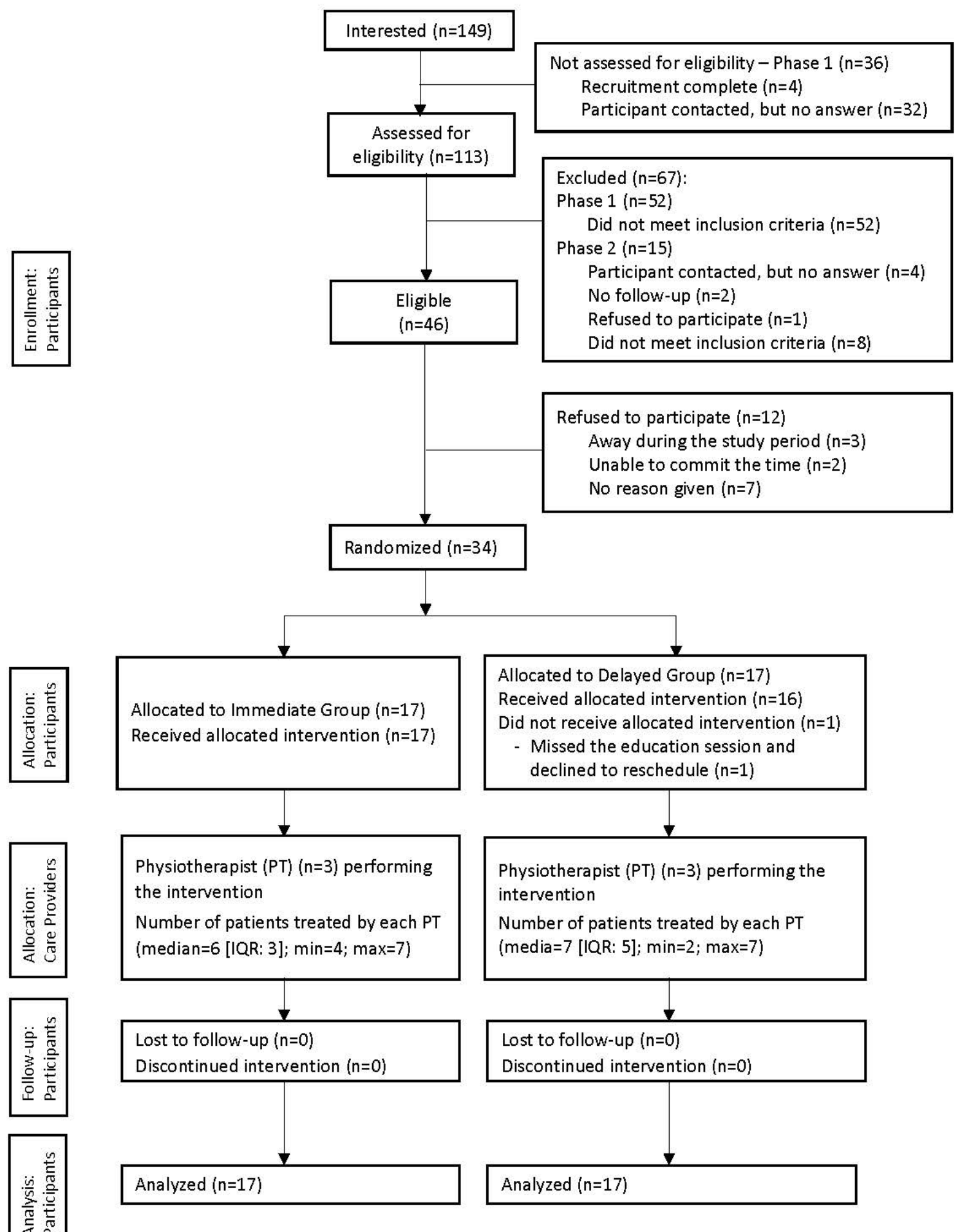


Figure 2. Results of outcome measures. (A) Bouted moderate to vigorous physical activity ( $\geq 3$ metabolic equivalent tasks [METs]). (B) Bouted moderate to vigorous physical activity ( $\geq 4$ METs). (C) Bouted sedentary time. (D) Knee Injury and Osteoarthritis Outcome Score (KOOS) symptoms subscale. (E) KOOS pain subscale. (F) KOOS activities of daily living subscale. (G) KOOS sports and recreation subscale. (H) KOOS quality of life subscale. (I) Partners in Health Scale.

A
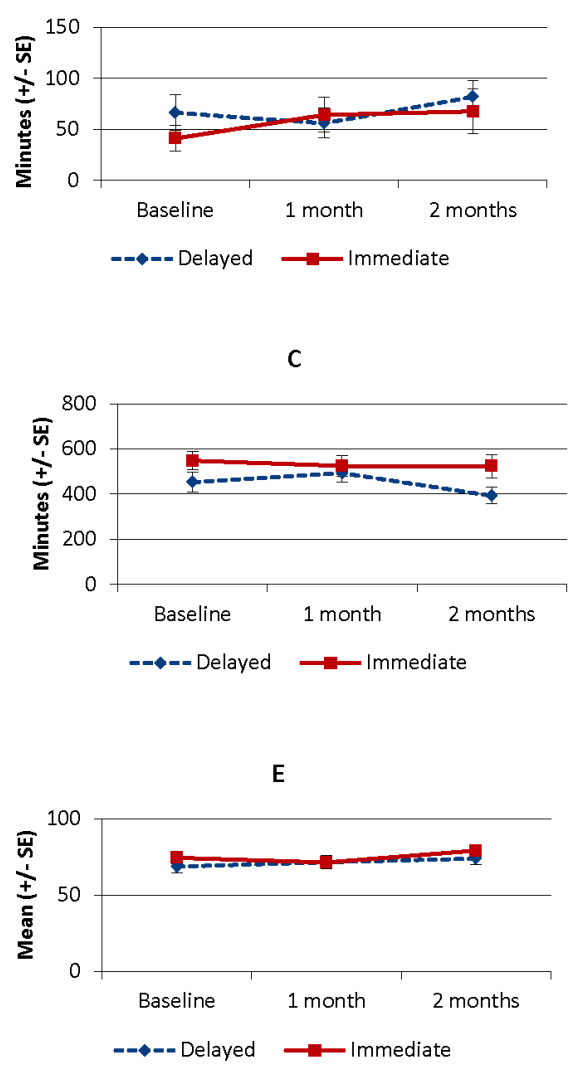

G

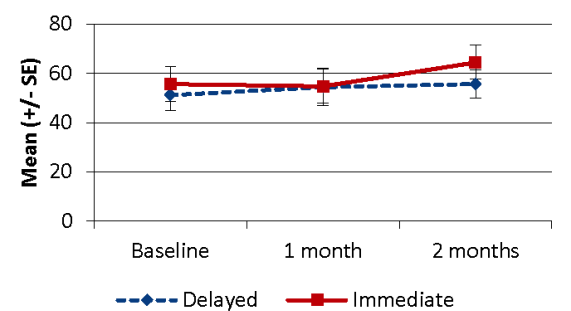

I

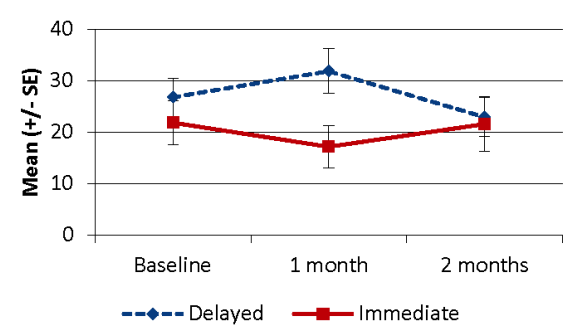

B

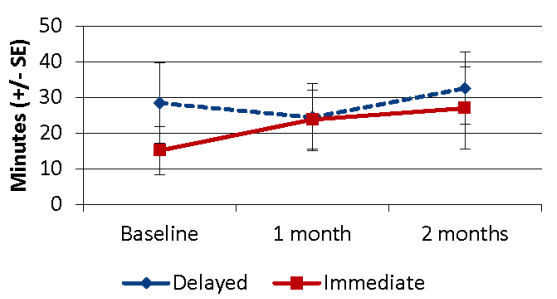

D

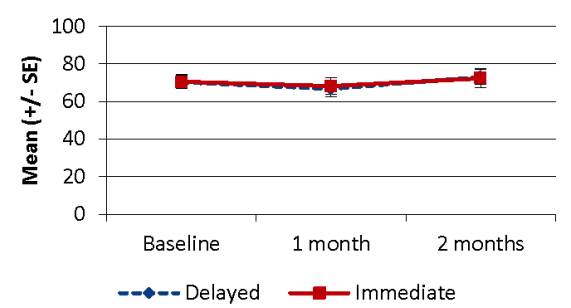

F

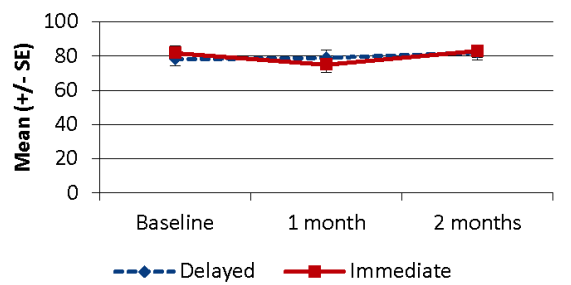

$\mathrm{H}$

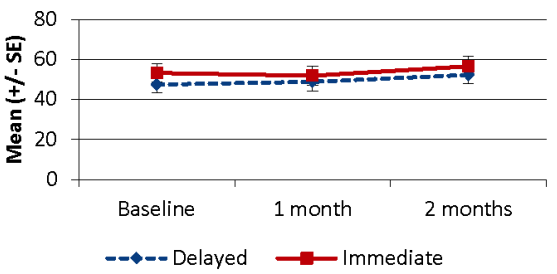


Table 3. Participant outcomes and results of contrast analyses.

\begin{tabular}{|c|c|c|c|c|c|c|c|c|c|}
\hline \multirow[t]{2}{*}{ Outcomes } & \multicolumn{3}{|c|}{$\begin{array}{l}\text { Immediate intervention } \\
(\mathrm{n}=17)\end{array}$} & \multicolumn{3}{|c|}{ Delayed intervention $(\mathrm{n}=17)$} & \multicolumn{3}{|c|}{$\begin{array}{l}\text { Adjusted group effect immediate intervention } \\
\text { vs delayed intervention coefficient }(95 \% \mathrm{CI})^{\mathrm{a}}\end{array}$} \\
\hline & $\begin{array}{l}\text { Base- } \\
\text { line }\end{array}$ & 1 month & 2 months & $\begin{array}{l}\text { Base- } \\
\text { line }\end{array}$ & 1 month & 2 months & Contrast 1 & Contrast 2 & Contrast 3 \\
\hline $\begin{array}{l}\text { Daily bouted MVPA }{ }^{\mathrm{b}}: \geq 3 \mathrm{METs}^{\mathrm{c}} \\
\text { (minutes), mean (SD) }\end{array}$ & $\begin{array}{l}41.3 \\
(51.6)\end{array}$ & $\begin{array}{l}64.2 \\
(70.5)\end{array}$ & $\begin{array}{l}67.7 \\
(85.8)\end{array}$ & $\begin{array}{l}66.5 \\
(71.0)\end{array}$ & $\begin{array}{l}56.0 \\
(60.1)\end{array}$ & $\begin{array}{l}81.9 \\
(64.4)\end{array}$ & $\begin{array}{l}-31.1 \\
(-56.6 \text { to }-5.7)\end{array}$ & $\begin{array}{l}4.6 \\
(-19.6 \text { to } 28.9)\end{array}$ & $\begin{array}{l}-11.0 \\
(-31.1 \text { to } 9.1)\end{array}$ \\
\hline $\begin{array}{l}\text { Daily bouted MVPA: } \geq 4 \text { METs } \\
\text { (minutes), mean (SD) }\end{array}$ & $\begin{array}{l}15.1 \\
(27.9)\end{array}$ & $\begin{array}{l}23.8 \\
(34.0)\end{array}$ & $\begin{array}{l}27.0 \\
(44.6)\end{array}$ & $\begin{array}{l}28.4 \\
(46.3)\end{array}$ & $\begin{array}{l}24.5 \\
(39.0)\end{array}$ & $\begin{array}{l}32.6 \\
(40.5)\end{array}$ & $\begin{array}{l}-10.5 \\
(-23.4 \text { to } 2.4)\end{array}$ & $\begin{array}{l}1.2 \\
(-9.6 \text { to } 12.0)\end{array}$ & $\begin{array}{l}-4.7 \\
(-12.0 \text { to } 2.6)\end{array}$ \\
\hline $\begin{array}{l}\text { Daily bouted sedentary time } \\
\text { (minutes), mean (SD) }\end{array}$ & $\begin{array}{l}548.4 \\
(169.1)\end{array}$ & $\begin{array}{l}524.9 \\
(192.1)\end{array}$ & $\begin{array}{l}523.9 \\
(200.2)\end{array}$ & $\begin{array}{l}453.3 \\
(180.5)\end{array}$ & $\begin{array}{l}492.8 \\
(164.8)\end{array}$ & $\begin{array}{l}393.1 \\
(144.2)\end{array}$ & $\begin{array}{l}51.4 \\
(-18.4 \text { to } \\
121.3)\end{array}$ & $\begin{array}{l}-83.6 \\
(-154.1 \text { to } \\
-13.1)\end{array}$ & $\begin{array}{l}-46.3 \\
(-109.0 \text { to } \\
16.4)\end{array}$ \\
\hline \multicolumn{10}{|c|}{ Knee Injury and Osteoarthritis Outcome Score ${ }^{\mathbf{e}}$ subscales, mean (SD) } \\
\hline Symptoms & $\begin{array}{l}70.6 \\
(15.8)\end{array}$ & $\begin{array}{l}68.3 \\
(18.4)\end{array}$ & $\begin{array}{l}72.5 \\
(20.2)\end{array}$ & $\begin{array}{l}70.4 \\
(14.9)\end{array}$ & $\begin{array}{l}66.8 \\
(18.2)\end{array}$ & $\begin{array}{l}73.2 \\
(15.4)\end{array}$ & $\begin{array}{l}-1.3 \\
(-7.5 \text { to } 5.0)\end{array}$ & $\begin{array}{l}6.9 \\
\text { (0.4 to } 13.5)\end{array}$ & $\begin{array}{l}3.8 \\
\text { (-3.9 to } 11.4)\end{array}$ \\
\hline Pain & $\begin{array}{l}74.5 \\
(16.2)\end{array}$ & $\begin{array}{l}71.4 \\
(17.5)\end{array}$ & $\begin{array}{l}79.1 \\
(13.0)\end{array}$ & $\begin{array}{l}68.6 \\
(16.1)\end{array}$ & $\begin{array}{l}71.6 \\
(15.2)\end{array}$ & $\begin{array}{l}74.0 \\
(15.4)\end{array}$ & $\begin{array}{l}3.9 \\
(-4.9 \text { to } 12.6)\end{array}$ & $\begin{array}{l}3.4 \\
(-4.3 \text { to } 11.1)\end{array}$ & $\begin{array}{l}5.0 \\
(-3.8 \text { to } 13.8)\end{array}$ \\
\hline Activities of daily living & $\begin{array}{l}81.8 \\
(17.1)\end{array}$ & $\begin{array}{l}75.1 \\
(19.7)\end{array}$ & $\begin{array}{l}83.0 \\
(14.9)\end{array}$ & $\begin{array}{l}78.3 \\
(15.9)\end{array}$ & $\begin{array}{l}79.1 \\
(18.9)\end{array}$ & $\begin{array}{l}82.2 \\
(17.1)\end{array}$ & $\begin{array}{l}7.2 \\
(-1.4 \text { to } 15.8)\end{array}$ & $\begin{array}{l}7.8 \\
(-1.2 \text { to } 16.9)\end{array}$ & $\begin{array}{l}8.4 \\
(-0.8 \text { to } 17.6)\end{array}$ \\
\hline Sport and recreation function & $\begin{array}{l}55.6 \\
(29.5)\end{array}$ & $\begin{array}{l}54.7 \\
(28.3)\end{array}$ & $\begin{array}{l}64.4 \\
(28.4)\end{array}$ & $\begin{array}{l}51.2 \\
(26.0)\end{array}$ & $\begin{array}{l}54.4 \\
(31.4)\end{array}$ & $\begin{array}{l}55.6 \\
(22.6)\end{array}$ & $\begin{array}{l}3.6 \\
(-8.2 \text { to } 15.4)\end{array}$ & $\begin{array}{l}-0.5 \\
(-11.0 \text { to } 10.0)\end{array}$ & $\begin{array}{l}3.2 \\
(-7.9 \text { to } 14.4)\end{array}$ \\
\hline Knee-related quality of life & $\begin{array}{l}53.3 \\
(18.4)\end{array}$ & $\begin{array}{l}51.8 \\
(19.5)\end{array}$ & $\begin{array}{l}56.6 \\
(20.2)\end{array}$ & $\begin{array}{l}47.4 \\
(16.1)\end{array}$ & $\begin{array}{l}48.9 \\
(19.3)\end{array}$ & $\begin{array}{l}52.3 \\
(18.0)\end{array}$ & $\begin{array}{l}2.6 \\
(-5.0 \text { to } 10.3)\end{array}$ & $\begin{array}{l}3.7 \\
(-3.0 \text { to } 10.4)\end{array}$ & $\begin{array}{l}5.5 \\
(-2.0 \text { to } 13.0)\end{array}$ \\
\hline Partners in Health ${ }^{\mathrm{f}}$, mean (SD) & $\begin{array}{l}21.9 \\
(17.6)\end{array}$ & $\begin{array}{l}17.2 \\
(17.0)\end{array}$ & $\begin{array}{l}21.6 \\
(21.9)\end{array}$ & $\begin{array}{l}26.8 \\
(15.3)\end{array}$ & $\begin{array}{l}31.9 \\
(17.9)\end{array}$ & $\begin{array}{l}22.9 \\
(15.2)\end{array}$ & $\begin{array}{l}10.9 \\
\text { (2.5 to } 19.3)\end{array}$ & $\begin{array}{l}-0.3 \\
(-10.3 \text { to } 9.7)\end{array}$ & $\begin{array}{l}1.9 \\
(-6.0 \text { to } 9.8)\end{array}$ \\
\hline
\end{tabular}

${ }^{\mathrm{a}}$ Outcome and baseline times are as follows: contrast 1: immediate intervention T0 to T1 vs delayed intervention T0 to- T1; contrast 2: immediate intervention $\mathrm{T} 0$ to $\mathrm{T} 1$ vs delayed intervention $\mathrm{T} 1$ to $\mathrm{T} 2$; contrast 3: immediate intervention $\mathrm{T} 0$ to $\mathrm{T} 1$ vs delayed intervention $\mathrm{T} 0$ to $\mathrm{T} 2$. Contrast models were adjusted for block sizes and baseline outcome measure.

${ }^{\mathrm{b}}$ MVPA: moderate to vigorous physical activity, performed in bouts $\geq 10$ minutes.

${ }^{\mathrm{c}}$ METs: metabolic equivalent tasks.

${ }^{\mathrm{d}}$ Sedentary behavior was performed in bouts $>20$ minutes.

${ }^{\mathrm{e}} \mathrm{S}$ cores range from 0 to 100 , with higher being better.

${ }^{\mathrm{f}} \mathrm{S}$ cores range from 0 to 96 , with lower being better.

Results from the imputation analysis (data not shown) were in line with the main missing-at-random analysis, in estimates, standard errors, and $P$ values of group effects. This suggests that the presence of missing data did not have an important effect on the findings. No adverse event associated with the intervention was reported by participants during the study.

\section{Discussion}

This study demonstrated the feasibility of a behavioral intervention, supported by the use of a wearable device, to promote physical activity. While our strategy yielded a recruitment rate below the goal of $80 \%$, we exceeded the target in participant and equipment retention in a community-based study. Since our eligibility criteria were in line with other physical activity intervention studies involving people with knee OA [4], we will use the same eligibility criteria and plan sufficient time for participant recruitment in the future RCT. Furthermore, with $88 \%$ of participants adhering to the study protocol and no adverse events reported, we have shown that the intervention and study protocol can be delivered within the resource constraints.

Our results have also demonstrated preliminary efficacy of the physical activity counselling program, with the immediate group showing a trend of improvement in MVPA ( $\geq 3$ METs) and the Partners in Health Scale compared with the delayed group at T0 to T1. Also, changes in MVPA appeared to be similar in both groups after they received the intervention. These findings are in line with previous studies on physical activity interventions, which generally result in short-term improvement (within 6 months) [4].

Results on sedentary behavior, however, were unexpected. While there was no noticeable effect at $\mathrm{T} 0$ to $\mathrm{T} 1$ between the 2 groups on these outcome measures, the intervention appeared to have a more favorable effect in the delayed group (T1 to T2) than in the immediate group (T0 to T1). One plausible explanation may be due to the counselling protocol. Although the program had separated physical activity and sedentary behavior into 2 counselling conversations, our approach might 
be more suitable for motivating people to be active than for encouraging them to sit less. We instructed the PTs to begin by asking participants about what they did to achieve the desired behavior (ie, being more active and sitting less) in a normal day. While this approach was logical for participants to set goals about their preferred physical activities, it might be less intuitive to think of ways to reduce sitting time, especially for those who had a sedentary occupation (eg, office workers or long-distance truck drivers). For them, focusing on what to do to reduce sitting highlighted the reality that participants had little control over this behavior, and therefore it might be challenging for them to set achievable goals. Similar issues have been raised by several recent systematic reviews on interventions to change activity behavior [47-49]. They concluded that, although programs targeting physical activity or combined activity and sedentary behavior are effective at improving physical activity participation, only the ones that are designed to change sedentary behavior achieve the best results in reducing sitting time. Given the challenge, it was possible that our study PTs needed time to practice and become comfortable with the sedentary counselling protocol. This might have contributed to the trend of improvement among participants who received the intervention later in the study. In light of the findings, we have refined the sedentary behavior counselling protocol with the study PTs and provided training sessions. The revised PT training protocol has been applied to 3 ongoing RCTs that are examining the efficacy of the program for patients with knee OA, rheumatoid arthritis, and systematic lupus erythematosus (ClinicalTrial.gov identifiers: NCT02315664; NCT02585323; NCT02554474). The first 2 registration numbers are for OA studies and the last number is for a study in people with rheumatoid arthritis and systemic lupus erythematosus.
Our result in the KOOS symptoms subscale was similar, with a significant difference found between the immediate group at $\mathrm{T} 0$ to $\mathrm{T} 1$ and the delayed group at $\mathrm{T} 1$ to $\mathrm{T} 2$. The reason for this is unclear, but it should be viewed in the context of the lack of a significant difference in other KOOS subscales, which are also associated with symptom severity. It should be noted that we did not adjust the analysis for multiple comparisons; hence, we cannot rule out the possibly that the results were due to chance.

This study has several limitations. First, we did not assess the full spectrum of feasibility. Although the study has identified strengths and areas of improvement for the intervention, we did not address demand (ie, intent to use) and acceptability (ie, intent to continue use and satisfaction) by people with arthritis [31]. Second, our sample was relatively active as indicated by the high bouted MVPA ( $\geq 3$ METs) minutes at baseline. Since patients who are inactive are more likely to need active intervention, improvement in our recruitment strategy is needed to ensure that we reach this population in the full RCTs. Finally, $82 \%$ of participants were women. Since men and women may respond to behavioral interventions differently, additional efforts are required to enroll men in order to permit analyses to examine the effect of sex on the behavioral and disease-related outcomes.

These limitations notwithstanding, in the Track-OA study we have developed a physical activity counselling program that is practical and can be implemented in a full RCT. We have also demonstrated that it is feasible to use an objective physical activity measure (ie, SenseWear) for data collection in the community. The results have contributed to refining the counselling protocol, the recruitment strategy, and the timeline for a series of studies to evaluate the efficacy of this program.

\section{Acknowledgments}

The authors are grateful for the support of patient and consumer collaborators, including Alison Hoens (Arthritis Research Canada, Arthritis Patient Advisory Board) and Cheryl Koehn (Arthritis Consumer Experts). We also thank Dr Charlie Goldsmith for his valuable guidance on the statistical analysis.

\section{Conflicts of Interest}

None declared.

\section{Multimedia Appendix 1}

Arthritis by physical activity. Data from Government of Canada, generated from: http://66.240.150.17:9600/PHAC/ readPPReports.jsp?l=en\&folder=iDE8F756E1ED845419EE7457066BB23D5.

[PDF File (Adobe PDF File), 64KB-Multimedia Appendix 1]

\section{References}

1. Brosseau L, MacLeay L, Robinson V, Wells G, Tugwell P. Intensity of exercise for the treatment of osteoarthritis. Cochrane Database Syst Rev 2003(2):CD004259. [doi: 10.1002/14651858.CD004259] [Medline: 12804510]

2. Ottawa Panel. Ottawa Panel evidence-based clinical practice guidelines for therapeutic exercises and manual therapy in the management of osteoarthritis. Phys Ther 2005 Sep;85(9):907-971. [Medline: 16117601]

3. Zhang W, Moskowitz RW, Nuki G, Abramson S, Altman RD, Arden N, et al. OARSI recommendations for the management of hip and knee osteoarthritis, part I: critical appraisal of existing treatment guidelines and systematic review of current research evidence. Osteoarthritis Cartilage 2007 Sep;15(9):981-1000 [FREE Full text] [doi: 10.1016/j.joca.2007.06.014] [Medline: 17719803 ] 
4. Fransen M, McConnell S. Exercise for osteoarthritis of the knee. Cochrane Database Syst Rev 2008 Oct 08(4):CD004376. [doi: 10.1002/14651858.CD004376.pub2] [Medline: 18843657]

5. McAlindon TE, Bannuru RR, Sullivan MC, Arden NK, Berenbaum F, Bierma-Zeinstra SM, et al. OARSI guidelines for the non-surgical management of knee osteoarthritis. Osteoarthritis Cartilage 2014 Mar;22(3):363-388 [FREE Full text] [doi: 10.1016/j.joca.2014.01.003] [Medline: 24462672]

6. Bliddal H, Christensen R. The management of osteoarthritis in the obese patient: practical considerations and guidelines for therapy. Obes Rev 2006 Nov;7(4):323-331. [doi: 10.1111/j.1467-789X.2006.00252.x] [Medline: 17038126]

7. Miller GD, Nicklas BJ, Loeser RF. Inflammatory biomarkers and physical function in older, obese adults with knee pain and self-reported osteoarthritis after intensive weight-loss therapy. J Am Geriatr Soc 2008 Apr;56(4):644-651. [doi: 10.1111/j.1532-5415.2007.01636.x] [Medline: 18312558]

8. Dunlop DD, Song J, Semanik PA, Chang RW, Sharma L, Bathon JM, et al. Objective physical activity measurement in the osteoarthritis initiative: are guidelines being met? Arthritis Rheum 2011 Nov;63(11):3372-3382 [FREE Full text] [doi: 10.1002/art.30562] [Medline: 21792835]

9. Li L. British Columbia Osteoarthritis Survey. Vancouver, BC: Arthritis Research Centre of Canada; 2008.

10. Wallis JA, Webster KE, Levinger P, Taylor NF. What proportion of people with hip and knee osteoarthritis meet physical activity guidelines? A systematic review and meta-analysis. Osteoarthritis Cartilage 2013 Nov;21(11):1648-1659 [FREE Full text] [doi: 10.1016/j.joca.2013.08.003] [Medline: 23948979]

11. Gyurcsik NC, Brawley LR, Spink KS, Brittain DR, Fuller DL, Chad K. Physical activity in women with arthritis: examining perceived barriers and self-regulatory efficacy to cope. Arthritis Rheum 2009 Aug 15;61(8):1087-1094 [FREE Full text] [doi: 10.1002/art.24697] [Medline: 19644901]

12. Kang HS, Ferrans CE, Kim MJ, Kim JI, Lee E. Aquatic exercise in older Korean women with arthritis: identifying barriers to and facilitators of long-term adherence. J Gerontol Nurs 2007 Jul;33(7):48-56. [Medline: 17672168]

13. Der Ananian C, Wilcox S, Saunders R, Watkins K, Evans A. Factors that influence exercise among adults with arthritis in three activity levels. Prev Chron Dis 2006 Jul;3(3):A81. [Medline: 16776882]

14. Thorp AA, Owen N, Neuhaus M, Dunstan DW. Sedentary behaviors and subsequent health outcomes in adults a systematic review of longitudinal studies, 1996-2011. Am J Prev Med 2011 Aug;41(2):207-215. [doi: 10.1016/j.amepre.2011.05.004] [Medline: 21767729]

15. van Uffelen JG, Wong J, Chau JY, van der Ploeg HP, Riphagen I, Gilson ND, et al. Occupational sitting and health risks: a systematic review. Am J Prev Med 2010 Oct;39(4):379-388. [doi: 10.1016/j.amepre.2010.05.024] [Medline: 20837291]

16. Dunstan D, Barr E, Healy G, Salmon J, Shaw J, Balkau B, et al. Television viewing time and mortality: the Australian Diabetes, Obesity and Lifestyle Study (AusDiab). Circulation 2010;121:384-391. [Medline: 20065160]

17. Owen N, Sparling P, Healy G, Dunstan D, Matthews C. Sedentary behaviormerging evidence for a new health risk. Mayo Clin Proc 2010 Dec;85(12):1138-1141. [Medline: 21123641]

18. Owen N. Sedentary behavior: understanding and influencing adults' prolonged sitting time. Prev Med 2012 Dec;55(6):535-539. [doi: 10.1016/j.ypmed.2012.08.024] [Medline: 22968124]

19. Healy GN, Dunstan DW, Salmon J, Cerin E, Shaw JE, Zimmet PZ, et al. Objectively measured light-intensity physical activity is independently associated with 2-h plasma glucose. Diabetes Care 2007 Jun;30(6):1384-1389. [doi: 10.2337/dc07-0114] [Medline: 17473059]

20. Healy GN, Wijndaele K, Dunstan DW, Shaw JE, Salmon J, Zimmet PZ, et al. Objectively measured sedentary time, physical activity, and metabolic risk: the Australian Diabetes, Obesity and Lifestyle Study (AusDiab). Diabetes Care 2008 Feb;31(2):369-371. [doi: 10.2337/dc07-1795] [Medline: 18000181]

21. Dunstan DW, Kingwell BA, Larsen R, Healy GN, Cerin E, Hamilton MT, et al. Breaking up prolonged sitting reduces postprandial glucose and insulin responses. Diabetes Care 2012 May;35(5):976-983 [FREE Full text] [doi: 10.2337/dc11-1931] [Medline: 22374636]

22. Talbot L, Gaines J, Huynh T, Metter E. A home-based pedometer-driven walking program to increase physical activity in older adults with osteoarthritis of the knee: a preliminary study. J Am Geriatr Soc 2003 Mar;51(3):387-392. [Medline: $\underline{12588583}$ ]

23. Bravata D, Smith-Spangler C, Sundaram V, Gienger A, Lin N, Lewis R, et al. Using pedometers to increase physical activity and improve health: a systematic review. JAMA 2007 Nov 21;298(19):2296-2304. [doi: 10.1001/jama.298.19.2296] [Medline: 18029834$]$

24. Lyons EJ, Lewis ZH, Mayrsohn BG, Rowland JL. Behavior change techniques implemented in electronic lifestyle activity monitors: a systematic content analysis. J Med Internet Res 2014;16(8):e192 [FREE Full text] [doi: 10.2196/jmir.3469] [Medline: 25131661]

25. Lewis ZH, Lyons EJ, Jarvis JM, Baillargeon J. Using an electronic activity monitor system as an intervention modality: a systematic review. BMC Public Health 2015 Jun 24;15:585 [FREE Full text] [doi: 10.1186/s12889-015-1947-3] [Medline: 26104189]

26. Clayton C, Feehan L, Goldsmith C, Miller W, Grewal N, Ye J, et al. Feasibility and preliminary efficacy of a physical activity counseling intervention using Fitbit in people with knee osteoarthritis: the TRACK-OA study protocol. Pilot Feasibility Stud 2015 Aug 22;1:30 [FREE Full text] [doi: 10.1186/s40814-015-0027-x] [Medline: 27965808] 
27. Marra C, Cibere J, Tsuyuki R, Soon J, Esdaile J, Gastonguay L, et al. Improving osteoarthritis detection in the community: pharmacist identification of new, diagnostically confirmed osteoarthritis. Arthritis Rheum 2007 Oct 15;57(7):1238-1244 [FREE Full text] [doi: 10.1002/art.23019] [Medline: 17907209]

28. Altman R, Asch E, Bloch D, Bole G, Borenstein D, Brandt K, et al. Development of criteria for the classification and reporting of osteoarthritis. Classification of osteoarthritis of the knee. Diagnostic and Therapeutic Criteria Committee of the American Rheumatism Association. Arthritis Rheum 1986 Aug;29(8):1039-1049. [Medline: 3741515]

29. Thomas S, Reading J, Shephard RJ. Revision of the Physical Activity Readiness Questionnaire (PAR-Q). Can J Sport Sci 1992 Dec;17(4):338-345. [Medline: 1330274]

30. Gutnick D, Reims K, Davis C, Gainforth H, Jay M, Cole S. Brief action planning to facilitate behavior change and support patient self-management. J Clin Outcomes Manag 2014;21:17-29.

31. Bowen DJ, Kreuter M, Spring B, Cofta-Woerpel L, Linnan L, Weiner D, et al. How we design feasibility studies. Am J Prev Med 2009 May;36(5):452-457 [FREE Full text] [doi: 10.1016/j.amepre.2009.02.002] [Medline: 19362699]

32. Thabane L, Ma J, Chu R, Cheng J, Ismaila A, Rios LP, et al. A tutorial on pilot studies: the what, why and how. BMC Med Res Methodol 2010 Jan 06;10:1 [FREE Full text] [doi: 10.1186/1471-2288-10-1] [Medline: 20053272]

33. Scheers T, Philippaerts R, Lefevre J. Variability in physical activity patterns as measured by the SenseWear Armband: how many days are needed? Eur J Appl Physiol 2012 May;112(5):1653-1662. [doi: 10.1007/s00421-011-2131-9] [Medline: 21874552]

34. Troiano RP, Berrigan D, Dodd KW, Mâsse LC, Tilert T, McDowell M. Physical activity in the United States measured by accelerometer. Med Sci Sports Exerc 2008 Jan;40(1):181-188. [doi: 10.1249/mss.0b013e31815a51b3] [Medline: 18091006]

35. Evenson KR, Goto MM, Furberg RD. Systematic review of the validity and reliability of consumer-wearable activity trackers. Int J Behav Nutr Phys Act 2015;12(1):159 [FREE Full text] [doi: 10.1186/s 12966-015-0314-1] [Medline: 26684758]

36. Feehan LM, Goldsmith CH, Leung AY, Li LC. SenseWearMini and Actigraph GT3X accelerometer classification of observed sedentary and light-intensity physical activities in a laboratory setting. Physiother Can 2016;68(2):116-123 [FREE Full text] [doi: 10.3138/ptc.2015-12] [Medline: 27909358]

37. Tierney M, Fraser A, Purtill H, Kennedy N. Study to determine the criterion validity of the SenseWear Armband as a measure of physical activity in people with rheumatoid arthritis. Arthritis Care Res (Hoboken) 2013 Jun;65(6):888-895 [FREE Full text] [doi: 10.1002/acr.21914] [Medline: 23213019]

38. Ainsworth B, Haskell W, Herrmann S, Meckes N, Bassett D, Tudor-Locke C, et al. The 2011 compendium of physical activities: tracking guide. Phoenix, AZ: Healthy Lifestyles Research Center, College of Nursing \& Health Innovation, Arizona State University; 2011. URL: https://sites.google.com/site/compendiumofphysicalactivities/tracking-guide [accessed 2017-06-05] [WebCite Cache ID 6r01VABcW]

39. Roos EM, Roos HP, Lohmander LS, Ekdahl C, Beynnon BD. Knee Injury and Osteoarthritis Outcome Score (KOOS)--development of a self-administered outcome measure. J Orthop Sports Phys Ther 1998 Aug;28(2):88-96. [doi: 10.2519/jospt.1998.28.2.88] [Medline: 9699158]

40. Roos EM, Roos HP, Ekdahl C, Lohmander LS. Knee injury and Osteoarthritis Outcome Score (KOOS)--validation of a Swedish version. Scand J Med Sci Sports 1998 Dec;8(6):439-448. [Medline: 9863983]

41. Petkov J, Harvey P, Battersby M. The internal consistency and construct validity of the partners in health scale: validation of a patient rated chronic condition self-management measure. Qual Life Res 2010 Sep;19(7):1079-1085. [doi: 10.1007/s11136-010-9661-1] [Medline: 20437206]

42. Latouche C, Jowett JBM, Carey AL, Bertovic DA, Owen N, Dunstan DW, et al. Effects of breaking up prolonged sitting on skeletal muscle gene expression. J Appl Physiol 2013 Feb 15;114(4):453-460 [FREE Full text] [doi: 10.1152/japplphysiol.00978.2012] [Medline: 23271697]

43. Howard BJ, Fraser SF, Sethi P, Cerin E, Hamilton MT, Owen N, et al. Impact on hemostatic parameters of interrupting sitting with intermittent activity. Med Sci Sports Exerc 2013 Jul;45(7):1285-1291. [doi: 10.1249/MSS.0b013e318285f57e] [Medline: 23439415]

44. Ory M, Resnick B, Jordan PJ, Coday M, Riebe D, Ewing GC, et al. Screening, safety, and adverse events in physical activity interventions: collaborative experiences from the behavior change consortium. Ann Behav Med 2005 Apr;29 Suppl:20-28. [doi: $10.1207 / \mathrm{s} 15324796 \mathrm{abm} 2902 \mathrm{~s}$ 5] [Medline: 15921486 ]

45. van Buuren S. Flexible Imputation of Missing Data. Boca Raton, FL: Chapman and Hall/CRC; 2012.

46. Almeida GJM, Wasko MC, Jeong K, Moore CG, Piva SR. Physical activity measured by the SenseWear Armband in women with rheumatoid arthritis. Phys Ther 2011 Sep;91(9):1367-1376 [FREE Full text] [doi: 10.2522/ptj.20100291] [Medline: 21719635]

47. Prince SA, Saunders TJ, Gresty K, Reid RD. A comparison of the effectiveness of physical activity and sedentary behaviour interventions in reducing sedentary time in adults: a systematic review and meta-analysis of controlled trials. Obes Rev 2014 Nov;15(11):905-919 [FREE Full text] [doi: 10.1111/obr.12215] [Medline: 25112481]

48. Martin A, Fitzsimons C, Jepson R, Saunders DH, van der Ploeg HP, Teixeira PJ, et al. Interventions with potential to reduce sedentary time in adults: systematic review and meta-analysis. Br J Sports Med 2015 Aug;49(16):1056-1063. [doi: 10.1136/bjsports-2014-094524] [Medline: 25907181] 
49. Commissaris DA, Huysmans MA, Mathiassen SE, Srinivasan D, Koppes LL, Hendriksen IJ. Interventions to reduce sedentary behavior and increase physical activity during productive work: a systematic review. Scand J Work Environ Health 2016 May 01;42(3):181-191. [doi: 10.5271/sjweh.3544] [Medline: 26683116]
Abbreviations
KOOS: Knee Injury and Osteoarthritis Outcome Score
METs: metabolic equivalent tasks
MVPA: moderate to vigorous physical activity
OA: osteoarthritis
PAR-Q: Physical Activity Readiness Questionnaire
PT: physical therapist
RCT: randomized controlled trial

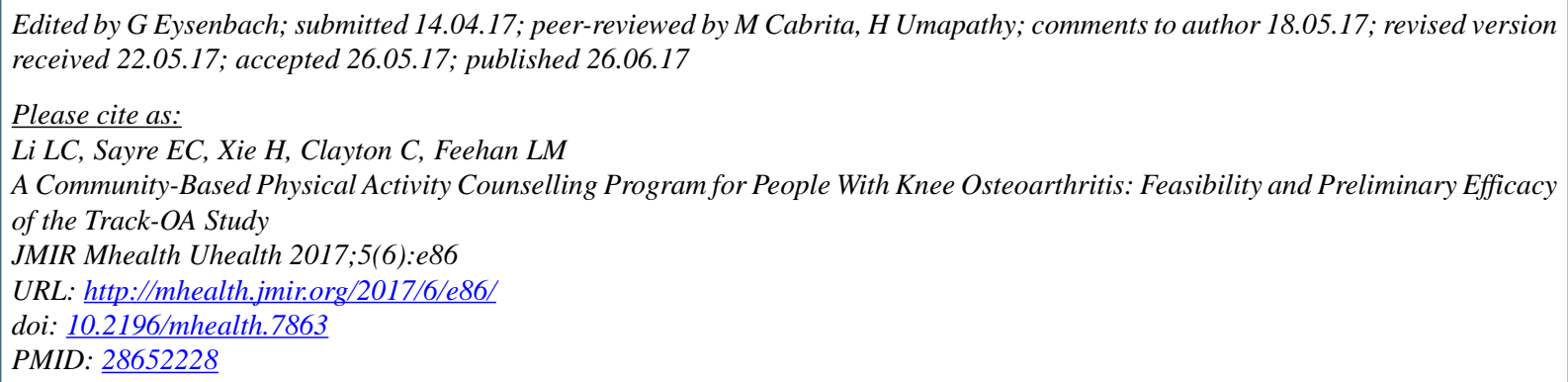

(CLinda C Li, Eric C Sayre, Hui Xie, Cam Clayton, Lynne M Feehan. Originally published in JMIR Mhealth and Uhealth (http://mhealth.jmir.org), 26.06.2017. This is an open-access article distributed under the terms of the Creative Commons Attribution License (https://creativecommons.org/licenses/by/4.0/), which permits unrestricted use, distribution, and reproduction in any medium, provided the original work, first published in JMIR mhealth and uhealth, is properly cited. The complete bibliographic information, a link to the original publication on http://mhealth.jmir.org/, as well as this copyright and license information must be included. 